\title{
A Review on Nanomaterial Revolution in Oil and Gas Industry for EOR (Enhanced Oil Recovery) Methods
}

\author{
Merum Sireesha ${ }^{1}$, Veluru Jagadeesh Babu ${ }^{1 *}$, S Kranthi Kiran ${ }^{1,2,3}$ and Seeram Ramakrishna ${ }^{1 *}$ \\ ${ }^{1}$ NUS Centre for Nanofibers and Nanotechnology, Department of Mechanical Engineering, Singapore 117581 \\ ${ }^{2}$ Department of Metallurgical and Materials Engineering, India \\ ${ }^{3}$ Department of Biotechnology, Bhupat and Jyoti Mehta School of Biosciences, 600036, India
}

*Corresponding author: Veluru Jagadeesh Babu, Department of Mechanical Engineering, Singapore

Seeram Ramakrishna, CtP ESP, Department of DHE NPD, Artificial Lift, Singapore Integration Center, Schlumberger, REDA Production Systems, 7 Benoi Crescent, Singapore 629971, Email: seeram@nus.edu.sg

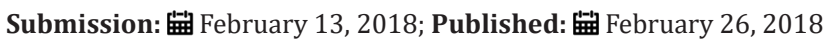

\begin{abstract}
Nanomaterials have explored everywhere in the day-to-day technologies, for instance nano circuits in electronics, bio-implants in medicine, aeroplane spare parts, photography and most recently in additive manufacturing (3D Printing). Nanomaterials have also introduced into oil and gas industry and evidenced in many aspects of exploration, drilling, production, refining and distribution. Variety of material hierarchies like nanofluids, nanocatalysts, nanoemulsions and nanocoatings in the upstream, midstream and downstream have explored. It is worth noting that the nanoparticles can reduce the viscosity of oil, increase the mobility ratio, and alter the reservoir permeability. Depending on the operational conditions of EOR methods, some nanoparticles perform more effective than other methods and lead to differ in EOR. However, tertiary fluids used for recovery or EOR process interact with the reservoir rock/ oil system where we EOR techniques are receiving substantial attention. Current studies on nanomaterials are seen as potential solutions to most of the challenges associated with the traditional EOR techniques. In this review, a brief discussion on the most recent developments of EOR mechanisms by using nanoparticles, nanofluids, nanoemulsions, nanocatalysts and nanocoatings. This review discussion also extended to discuss about existing challenges and opportunities for the future applications of nanostructures in EOR methods.
\end{abstract}

Keywords: Nanotechnology; Oil and gas EOR; Nanoparticles; Nanocatalysts; Nanosensors

\section{Introduction}

The energy consumption has increased enormously and consequently where oil resources have reached the phase with the production rate is near dead-end. Hence, the forefront challenge is have either to investigate a new technology or give alternative solution such as enhancement of oil recovery (EOR) to delay the energy crisis. Exhaustion of conventional light oil (1.02 trillion barrels) is much lesser than the unconventional heavy oil (5.6 trillion barrels) and it is estimated that approximately 434 and 650 billion barrels of heavy oil and bitumen may be recovered under certain limitations in the current technologies. This is mainly due to the nature of their physical and chemical properties as well as their geological difficulties. Recently, the development of nanotechnology has enabled one to harvest hydrocarbon from unconventional resources effectively and efficiently. For example, several types of nanocatalysts such as nano-sized transition metals and metal oxide nanoparticles have been used in processing heavy and extra heavy oil production for enhancement of oil recovery
(EOR). Nanotechnology created a revolution introduced in almost all fields since last five decades. Nanotechnology is one of the most active research areas well established in industry, aerospace, electronics, medicine, smart materials, Cosmetics, photography, energy etc. The fast growth of nanotechnology in different fields is because of the wide range of technological phenomena that focus on the properties of nanometre scale ranging from 0.1 to $100 \mathrm{~nm}$ in which the properties totally differ from their bulk counter parts. [1-5]. and t must be Capital, the atoms present in the nanoparticles are much lesser than the atoms present in the bulk materials but the physical and chemical properties are mostly constant in both cases. In addition, nanoparticles exhibit unique optical behaviour, heat resistant, magnetism, catalytic activity, melting point and internal pressure alteration. These unique tunable properties allow researchers to use nanosize materials in cost effective industrial processes with a predesign and manipulated properties [6].

The rapid advancement of nanotechnology has led to the 
application of various nano-sized devices and tools for oil and gas industry. Oil industry is divided into three main sectors. Upstream industry, also known as exploration and productions, which locates the crude oil and natural gas from reservoirs; Midstream industry includes processes like storage, transportation and marketing the crude oil, natural gas and natural gas liquids and the Downstream includes petrochemical plant, oil refining and then distribution. Many nanotechnology applications are already applied upstream oil industry, i.e., paramagnetic nanoparticles utilised for evaluation and oil saturation determination in large volumes of oil reservoirs by the detection of the water-oil menisci in reservoir rocks and utilizing the concept of enhancing magnetic resonance imaging [7-9]. Besides, the nano-emulsions and nanofoams can be used as conformance control agents for enhanced oil recovery $[10,11]$ and CO2 flooding [12]. The nano-technological applications in downstream sector are extensively, being used, for example, usage of nanostructured zeolites increased the extraction $40 \%$ of more gasoline than other catalysts. Developing the better material is the most obvious applications of nanotechnology for upstream operations $[13,14]$. The oil industry needs very strong, stable materials on a nanoscale, which could produce equipment that is lighter, more resistance offshore platforms and structures for midstream sector [15]. Injecting the nanoparticles to improving all conventional EOR methods is one of the main targets. Engesetin work observed that these tiny particles could penetrate into the pore spaces unlike conventional recovery techniques resulted in higher recovery, and explained that nanoparticles could be tailored to alter reservoir properties such as wettability, improve mobility ratio, or control formation fines migration. Since then research in this area was invoked. However, there are major challenges need to be addressed [16], this review attempted to summarize the significant research results from the different nanoparticles such as, nano fluids, nanosensors, nanocatalysts and nanocoatings in EOR.

\section{Nanofluids in EOR}
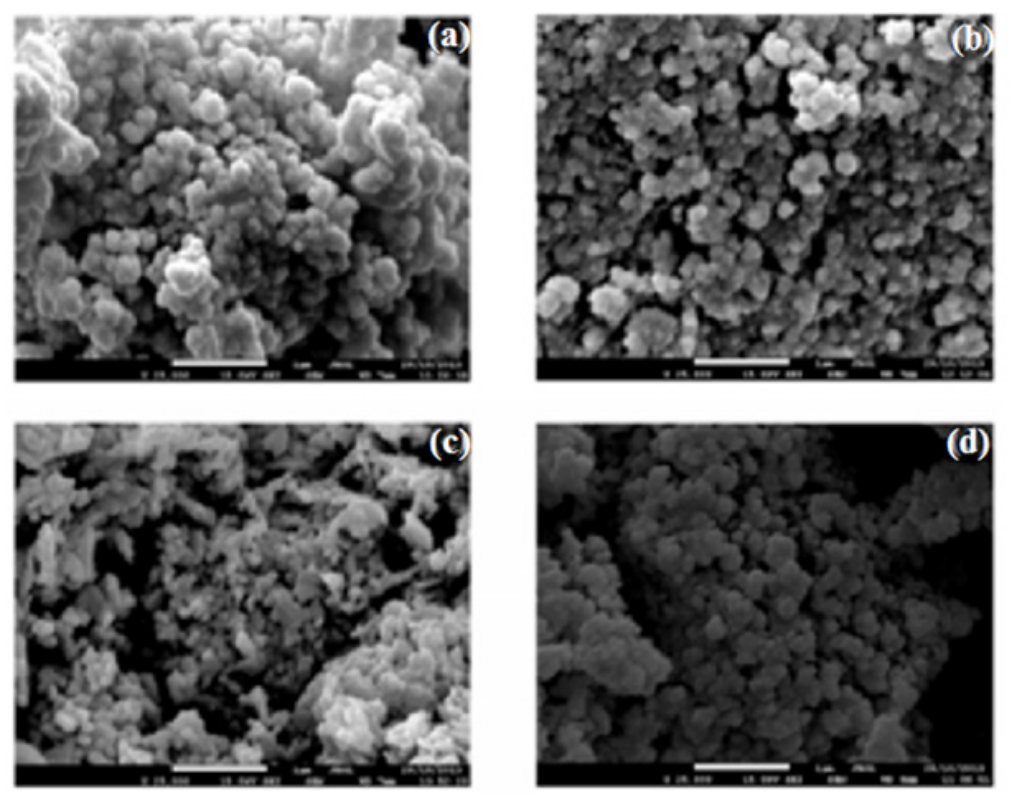

Figure 1: FESEM images of Nanoparticles (a) $\mathrm{TiO}_{2}$; (b) $\mathrm{Al}_{2} \mathrm{O}_{3}$; (c) NiO; ( delete this $\mathrm{sio}_{2}$ as it is ceramic substance please include any other image related to metal oxides.

Nanofluids or smart fluids is a suspension of particle size less than $100 \mathrm{~nm}$ in low volumetric fractions to a base fluid(any liquid such as oil, water and gas. The nanofluids are formed by adding NPs in water (or) brine. The traditional oil recovery methods is by means of thermal, gas and chemical are effective but have so many important challenges such as high process cost, less sweeping of oil from the rock substrate, heat leakage to the undesired layers, unfavourable mobility ration, asphaltene deposition etc. Therefore cost effective,eco-friendly EOR are greatly needed [17]. In nanofluids, nanoparticles arrange themselves to a wedge shaped film due to the pressure created in the injected fluids. The advantages of the nanofluids are interfacial tension reduction, tuning of wettability, viscosity increase of injection fluids than oil in reservoir, thermal conductivity and preventing asphaltene precipitation. Nanofluids can be used in a wide range of methods such as drilling, cementing, and EOR. The better performance in changing the rock wettability than surfactant/polymer is based on core-displacement investigation. This is due to easy flow of nanoparticle (diameter $<100 \mathrm{~nm}$ ) which is much lesser than rock porous medium (pore size $1 \mu \mathrm{m}$ ) [18]. An experimental study by Suleimanov and co-workers has proven that nanofluids containing water suspension of nonferrous metal nanoparticles and an anionic surfactant sulfonate-alkyl aryl sodium sulfonate were able to increase the oil displacement efficiency by $35 \%$ compared to that obtained using only surfactant solution. Roustaei et al. [19] investigated special type of NPs named Polysilicon which are very promising materials to be used in near future for enhanced oil recovery. They used hydrophobic and lipophilic polysilicon (HLP) and naturally wet polysilicon (NWP) are three types of Polysilicon NPs used according the reservoir wettability conditions 
as EOR agents in water-wet sandstone rocks. Both HLP and NWP Nano fluids improve oil recovery by interfacial tension reduction and wettability alteration to less water-wet condition. NWP and HLP NPs have stronger impact on rock wettability and higher influence on reduction of oil-water interfacial tension respectively. Zargartalebi et al. [20] reported in his experiments that hydrophilic and partially hydrophobic silica nanoparticles were able to improve surfactant sodium dodecyl sulfate performance during flooding. By the addition of NPs it is observed that the adsorption of the surfactant was significantly reduced, and lead to the generation of a piston- like flow behaviour throughout the porous medium, which improves the sweeping efficiency. Maghzi et al. [21] studied the impact of silica nanoparticles in polymer flooding. Many factors affect the wettability alteration caused by nanofluids such as NPs size, concentration and water salinity. Li et al. [22] conducted contact angle measurement of crude oil nanofluids with various concentrations of synthetic silica, and concluded that water wettability is directly proportional to the NP concentration.
Hendraningrat et al. [23], Amott-test method studies showed that the NP size can influence the contact angle of aqueous phase. This is because of high electrostatic repulsion force between the NPs. In addition, Hendraningrat et al. [24] found that the alterations in wettability depend not only on the size of NPs but also on the degree of water salinity, ionic composition, initial porous medium wettability, and duration of NP interaction in the fluid-rock system. Al-Anssari et al. [25] observed that NP adsorption was mainly irreversible, although a partial reversibility is existed once the surface is washed with acetone and/or distilled water. Different types of nanofluids with metal oxides, organic and inorganic particles are listed in Table 1 for EOH. Figure 1, shows the different types of nanoparticles used in EOR. Sun et al. [17] reported in his short review different nanoparticles have showed the different levels of EOR. In addition, Anssari et al. [26] reported the metal oxide nanoparticles showed better EOR from limestone at different temperature regime as presented in Figure 2 \& 3.

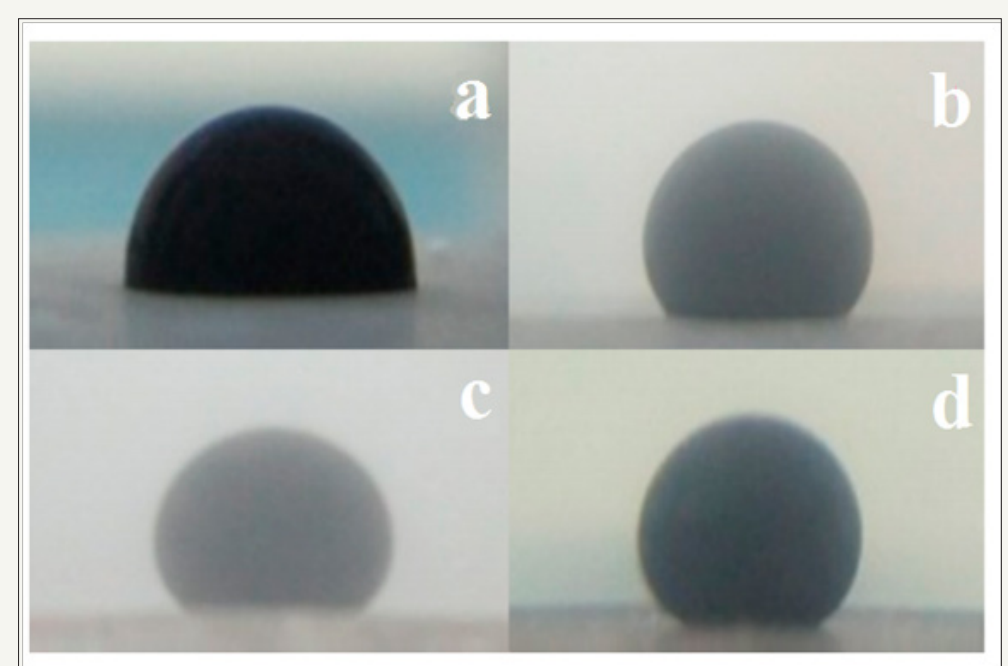

Figure 2: Microscopic image from oil droplet at temperature specific $26^{\circ} \mathrm{C}$ in the presence of (a) brine (b) $\mathrm{Al}_{2} \mathrm{O}_{3},(\mathrm{c}) \mathrm{TiO}_{2}$, (d) CoMo.

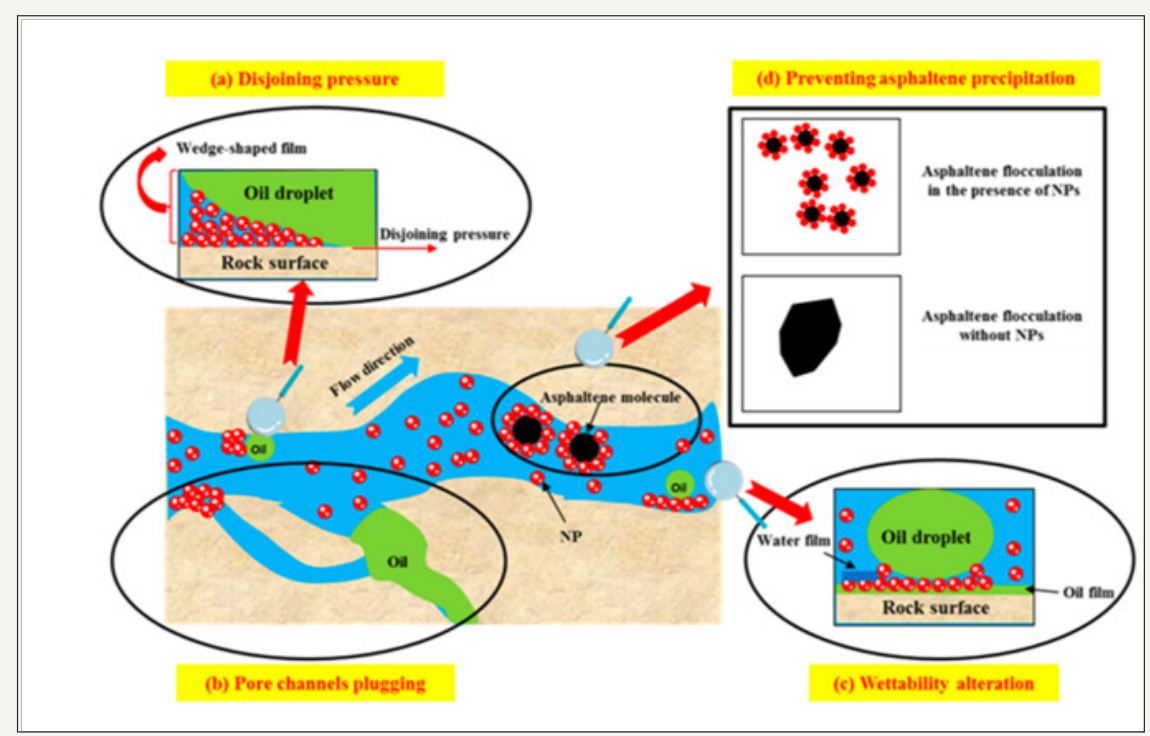

Figure 3: Schematic representation of EOR mechanism of nanofluids. 
Table 1: Nanofluids for the EOR and their increase recovery.

\begin{tabular}{|c|c|c|c|}
\hline Nanofluids & $\%$ of Increase Oil Recovery & Remarks & Ref. \\
\hline $\mathrm{Al}_{2} \mathrm{O}_{3}$ & - & $\begin{array}{l}\text { Berea sand stone, Aluminum Oxide } \\
\text { Nps not stable in brine by adding } \\
\text { Polyvinylpyrrolidone (PVP) increased the } \\
\text { stability of the nanofluid making as a good } \\
\text { agent for EOR. }\end{array}$ & Bayat [26], Hendraningrat [27] \\
\hline Copper(II) oxide $(\mathrm{CuO})$ & $71 \%$ & $\begin{array}{l}\text { Berea sand stone, (Poly-Di-Methyl-Siloxane } \\
\text { (PDMS)) and } \mathrm{CO}_{2} \text { used during EOR, could } \\
\text { increase the Cuo nanofluids viscosity } \\
\text { significantly while decrease the viscosity of } \\
\text { the oil }\end{array}$ & Shah [28] \\
\hline Iron oxide, $\left(\mathrm{Fe} 2 \mathrm{O}_{3} / \mathrm{Fe}_{4} \mathrm{O}_{4}\right)$ & $82.5 \%$ & $\begin{array}{l}\text { Iron oxide particles can be a legitimate EOR } \\
\text { by effectively reduces the viscosity, when } \\
\text { Diesel selected as a dispersing agent. }\end{array}$ & Ogolo et al. [29] \\
\hline Nickel oxide $\left(\mathrm{Ni}_{2} \mathrm{O}_{3}\right)$ & $85 \%$ & $\begin{array}{l}\text { Hydrophilic metal oxide. More effective than } \\
\text { Iron oxide nanoparticles high recovery when } \\
\text { brine solution was used. }\end{array}$ & Ogolo et al. [29] \\
\hline Magnesium oxide (MgO) & - & $\begin{array}{l}\text { Control fines migration, Ethanol and } \\
\text { magnesium oxide nanoparticles solution } \\
\text { could reduce the oil viscosity. MgO } \\
\text { nanoparticles are weak recovery agents for } \\
\text { EOR in sandstone reservoirs. }\end{array}$ & Ogolo et al. [29] \\
\hline $\mathrm{TiO}_{2}$ & $80 \%$ & $\begin{array}{l}\mathrm{TiO}_{2} \mathrm{NPs} \text { deposition in the porous surface } \\
\text { of the rock reduce the oil-brine Inter } \\
\text { Facial Tension, wettability alteration is the } \\
\text { dominant mechanism. }\end{array}$ & Hendraningrat [27] \\
\hline Tinoxide $\mathrm{SnO}_{2}$ & & $\begin{array}{l}\text { Increases the oil recovery in sandstone cores } \\
\text { while dispread in distilled water. Decreases } \\
\text { the recovery factor with ethanol or brine as } \\
\text { dispersing agents }\end{array}$ & Ogolo et al. [29] \\
\hline Zinc oxide $(\mathrm{ZnO})$ & - & $\begin{array}{c}\text { Similar to MgO NPs, Might be not suitable for } \\
\text { oil recovery because of the agglomeration } \\
\text { NPs at the site of the injection }\end{array}$ & Ogolo et al. [29] \\
\hline Zirconium oxide $\left(\mathrm{ZrO}_{2}\right)$ & - & $\begin{array}{l}\mathrm{ZrO}_{2} \text { injected at room temperature into } \\
\text { a sandstone core sample. No significant } \\
\text { increase in oil recovery when distilled } \\
\text { water is used, even reduces when brine and } \\
\text { ethanol is used. }\end{array}$ & Myloslavskyy et al. [30] \\
\hline Ferromagnetic nanoparticles & - & $\begin{array}{l}\text { Studies on Direct ferromagnetic NPs } \\
\text { were not available. Surfactant coated } \\
\text { ferro magnetic NPs were used to avoid } \\
\text { agglomeration. The isolated oil bubbles are } \\
\text { trapped in the centre of the pores, Ferro } \\
\text { Fluid makes the bubbles to collapse. It } \\
\text { can be used in both oil-wet and water-wet } \\
\text { reservoirs for Interfacial reduction. }\end{array}$ & Kothari et al. [31] \\
\hline Cobalt ferrite $\left(\mathrm{CoFe}_{2} \mathrm{O}_{4}\right)$ & - & $\begin{array}{c}\mathrm{CoFe}_{2} \mathrm{O}_{4} \text { increase in recovery by absorption } \\
\text { of electromagnetic waves that decreases the } \\
\text { oil viscosity.1\% of SDS is used as a stabilizer } \\
\text { to create the highest suspension layer in the } \\
\text { emulsion. }\end{array}$ & Yahya et al. [32] \\
\hline Carbon nanoparticles & $36 \%$ & $\begin{array}{l}\text { MWNT fluid as an EOR agent for } \\
\text { high-temperature and high-pressure } \\
\text { reservoirs. Core flood studies with and } \\
\text { without electromagnetic waves. Oil } \\
\text { recovery is doubled with the existence of } \\
\text { electromagnetic waves. }\end{array}$ & Chandran [33] \\
\hline
\end{tabular}




\begin{tabular}{|c|c|c|c|}
\hline SiO2 nanoparticle & $56 \%$ & $\begin{array}{l}\text { Cost effective nanoparticles, suitable } \\
\text { for water-wet sandstone reservoirs, no } \\
\text { stabilizers required. Thermally stable upto } \\
650{ }^{\circ} \mathrm{C} \text { the wettability alteration from water } \\
\text { wet Berea sandstone to intermediately -wet } \\
\text { is the dominant mechanism for oil recovery. } \\
\text { Main drawback in using this nanoparticle is } \\
\text { its tendency to aggregate to larger size. }\end{array}$ & Wang et al. [34], Wang et al. [35] \\
\hline Zeolite & $40 \%$ & $\begin{array}{l}\text { One of the main challenges in the } \\
\text { EOR process is the presence of high } \\
\text { concentrations of cations. Zeolite might be } \\
\text { helpful in adsorbing cations such as } \mathrm{Na}^{+}, \\
\mathrm{K} \mathrm{Ca}^{2+} \text {, and } \mathrm{Mg}^{2+} \text { from the formation water, } \\
\text { especially in high salinity conditions. }\end{array}$ & Skauge et al. [36] \\
\hline $\begin{array}{l}\text { Colloidal Dispersion Gels } \\
\text { (CDG) }\end{array}$ & $40 \%$ & $\begin{array}{l}\text { Better performance than polymer and silica } \\
\text { nanoparticles in mobilizing the residual oil } \\
\text { left behind from a primary flood. }\end{array}$ & Luo et al. [37] \\
\hline $\begin{array}{l}\text { Polyacrylamide Micro-gel } \\
\text { nanospheres }\end{array}$ & $66 \%-78 \%$ & $\begin{array}{l}\text { High cost. Low in polymer content. } \\
\text { Prominently the incremental oil recovery } \\
\text { factor by nanoparticles usually is below } 5 \% \\
\text { of the OOIP in a saline environment ( } 2 \mathrm{wt} \% \\
\text { or higher } \mathrm{NaCl} \text { content) in low concentration } \\
(0.01 \mathrm{wt} \%)\end{array}$ & Hashemi et al. [38] \\
\hline
\end{tabular}

\section{Nanocatalyst in EOR}

Nano catalysts exhibits unique catalytic and absorption/ adsorption properties due to their extraordinary active surface sites. In-situ catalytic upgrading of heavy oil with the help of metallic Nano catalysts is a promising cost effective and ecofriendly technology for production of high quality oils that meet pipeline and refinery sectors. Nano catalysts could be employed as inhibitors for asphaltene precipitation and subsequently enhance oil recovery. However, these new technology facing obstacle while employing nanoparticles for in-situ catalytic upgrading \& recovery enhancement. Good catalytic properties, such as high porosity and resistance to pore plugging are favourable properties for processing of heavy feedstock [39,40]. Different types of NPs have been used widely in the oil \& gas applications (from exploration to production) due to their unique physical \& chemical properties. Both noble and transitional metal nanoparticles are used mainly as catalyst in many petroleum processes such as catalytic reforming, in-situ aquathermolysis, hydrocracking and hydrodesulphurization $[3,41]$. This is mainly due to their large surface area-to-volume ratio in comparison to their bulk counter-parts, which significantly improves their catalytic activities and selectivity process [42]. Recent investigation revealed that nanocatalysts such as Ni NPs with mean particle size $6.3 \mathrm{~nm}$, which was prepared with surfactant named methyl cyclohexane-water-n-octanol-AEO 9, was capable to reduce the viscosity of heavy oil sample from Liaohe oilfield by 98.9\% [4]. The experimental results also demonstrated that the molecular weight of the feedstock was decreased notably due to the reduction of sulphur content by nearly $50 \%$ and the amount of resin by $15.83 \%$ and asphaltene by $15.33 \%$. Several other types of nanocatalysts in aquathermolysis has also been reported elsewhere [2,41]. Shokrlu et al. [42] developed the nickel NPs with concentration of 500ppm influenced in viscosity reduction from $2700 \mathrm{mPa}$.s to $1900 \mathrm{mPa}$.s. Pore plugging the major hurdle in terms of recovery, to overcome this problem ultra-dispersed nanocatalysts were developed for industrial applications [43]. The dispersion is a very important criterion in catalyst industry and looking for ultra-dispersed (UD) catalysts to achieve higher conversion at the applied pressure and temperature conditions [44-46].

Nanocatalyst increases the productivity of the upgrading process due to the high mobility and high surface area of the nanocatalyst. In order to make possible longer run times, neither fixed bed catalyst nor the replacement of catalyst is required [47]. Nanocatalyst can obtain by mixing precursor salt and other reducing agent in the form of microemulsions [48]. The formulation of nanoparticles in w/o micro emulsions such as $\mathrm{Fe}$, $\mathrm{Pt}, \mathrm{Ni}, \mathrm{Au}, \mathrm{Cd}, \mathrm{Pd}, \mathrm{Ag}$ and $\mathrm{Cu}$ has been reported by Capek especially for in-situ applications such as upgrading and recovery of bitumen, and thus these micro emulsions considered as a breakthrough for nanocatalyst preparation. For heavy oil conversion, an emulsion was developed in presence of water claiming steam cracking of vacuum gas oil (VGO) catalysed by catalytic emulsion [49] Furthermore, a catalytic nanoparticle solution prepared by decomposition of w/o emulsion was successfully executed to catalyse hydro processing reaction [50,51]. Thompson et al studied 'Mo' nanoparticles as nanocatalysts performance for Athabasca bitumen upgrading [44]. To overcome UD nanocatalysts upgrading difficulties, more control systems is required to avoid or mitigate any associated risks. High level of control systems is required to avoid the pore plugging and even explosion because of the Presence of hydrogen as well as high pressure and temperature conditions. In Athabasca oil sands porous packed bed column, the transportal behaviour of ultradispersed multimetallic ( $\mathrm{Ni}-\mathrm{Mo}-\mathrm{W}$ ) nanocatalysts is investigated at high pressure and temperature of typical SAGD conditions (i.e., presence of reaction) and the effects of temperatures and permeability was reported by Hashemi et al. [51]. Experiment results showed that aggregation of nanocatalysts was observed and 
the deposition tendency for nanocatalysts is strongly affected by the type of metal, temperature, and sand permeability. In another study CoMo nanocatalysts on alumina for HDS of thiophene was investigated [52]. The fluorine-modified CoMo nanocatalysts showed a very high HDS catalytic activity and were able to selectively and significantly convert nearly $100 \%$ of thiophene. Mohammed etal has successfully developed a new type of catalyst by homogeneously implanting CoMo on the structure of multiwalled carbon nanotubes (CoMo/m-CNT). The simple fabricated CoMo/ CNT catalytic ability in HDS reaction was compared with the conventional $\mathrm{CoMo} / \mathrm{Al}_{2} \mathrm{O}_{3}$ [53]. The experimental results revealed that the integration of $(\mathrm{CoMo} / \mathrm{m}-\mathrm{CNT})$ was able to provide a better catalytic activity than $\mathrm{CoMo} / \mathrm{Al}_{2} \mathrm{O}_{3}$ catalyst in removing sulphur from gasoil. It is supposed that CNTs could provide a better metalsupport interaction and electronic effect on the catalyst surface and improves its adsorption affinity. From few years onwards nanocatalysts such as metal oxide nanoparticles have been used in hydro processing of crude oil due to their good adsorption/ oxidation of asphaltenes, high oxygen storage/release capacity. For example, Montoya and co- workers reported the effect of $\mathrm{NiO}$ and PdO endured on fumed silica nanoparticles catalysts in catalytic thermal cracking of n-C7 asphaltenes [54]. Based on their results, it was endorsed that the presence of $\mathrm{NiO}$ or $\mathrm{PdO}$ was capable to show a more desirable catalytic activity than fumed silica support alone. In addition, it is also reported that bimetallic (both $\mathrm{NiO}$ and $\mathrm{PdO}$ ) on silica nanoparticles support showed the highest catalytic activity support the strength of the catalyst to effectively reduced the reaction activation energy at noticeably low temperature. In other study, distinct types of metal oxide nanoparticles, including $\mathrm{CeO}_{2}$, $\mathrm{Co}_{3} \mathrm{O}_{4}, \mathrm{MnO}_{2}$ and the two free $\alpha-\mathrm{Fe}_{2} \mathrm{O}_{3}$ and $\mathrm{SiO}_{2}$-supported $\alpha-\mathrm{Fe}_{2} \mathrm{O}_{3}$ were used beside along supercritical water (SCW) in hydrocracking of heavy petroleum residue attained against the vacuum distillation unit [55-57].

\section{Nanosensors \& Nanoreporters in EOR}

Prediction and exploration of oil and gas beneath the earth crust is the toughest activity because of the unexpected geological hazards that often increase the production cost. Conventional sensing technologies provide very little information about the reservoir characteristics. Modern sensing technologies are quiet not able to attain high-resolution reservoir imaging and inadequate to penetrate deeply into reservoir to get key information about reservoir characteristics. Furthermore, many sensing techniques like conventional electrical sensors are usually unable to implement decisive information at certain extreme reservoir conditions. Despite the improvement of new state-of-the-art exploration techniques such as 3D and 4D seismic surveys, unique, elementary, low-cost, non- damaging and sensitive sensing technologies that can precisely detect the hydrocarbon accumulation are still desired. The assimilation between new reservoir mapping and computational scenario is also needed to get better discovery, sizing and characterization of reservoirs. Application of nanotechnology in accurate prognosis of hydrocarbon accumulations and characterization of hydrocarbon reservoirs has been broadly studied. Due to the advantage of their size-dependent optical, magnetic, chemical and electrical properties, nanoparticles can be used as nanosensors as they direct easily to migrate through pores of the enclosing geological structures and compile information about the reservoir characteristics. Current sensing technology based on nanoparticles also facilities one to probe rock properties in deeper reservoir regions and to recover the data about the complicate interaction between reservoir rock and fluids or distribution of immiscible fluids. One of the most extensively studied technologies in the application of magnetic nanoparticles for electromagnetic (EM) based reservoir mapping and characterization [58,59]. It is supposed that magnetic nanoparticles have the competence to provide high-resolution magnetic measurement by dynamic magnetic permeability of the rock construction and reservoir fluids at actual low frequencies [60]. The magnetic nanoparticles was proven that, it is able to probe the transport of immiscible fluids as they can easily be designed to be as a substitute of adsorbed at oil-water interface [58]. Present, the detection is based on the creation of interfacial variations and pressure (sound) waves as the result of the action of nanoparticles adsorbed at the interface of either oil- water or air-water owed to an external magnetic field. This approach is called as magneto-acoustic tomography. Superparamagnetic iron oxide (SPIO) nanoparticles can also be used as contrasting agent in NMR (nuclear magnetic resonance) imaging for the characterization of porous rock formation. In a recent study by Park et al, reported SPIO nanoparticles were able to increase the contrast of NMR logging by shortening NMR T2 relaxation time [61]. Similar to the application of SPIO nanoparticles in other applications corresonding as in magnetic resonance imaging (MRI), assessement on the quantity of the nanoparticles is possible since the concentration of the nanoparticle is reciprocal with the change of relaxation rate DR2 (reciprocal of the relaxation time, 1/T2) [62]. The nanoparticles are expected to act as NMR nanosensor where the NMR relaxometry can directly be execute inside the formation at the wellbore or in the fluid sample withdraw from the well [61]. It is reported that the non-covalent attachment of triheptylamine (a probe molecule) onto sulphated PVA-OCB (which then called as nanoreporter) can be injected into oil reservoir and used to access accurate information about subsurface oil contents. In this advent, the nano reporter helps triheptylamine probe molecules travel through rock formation and carefully discharge them whenever the rock contains oil [63]. Especially, the information about downhole hydrocarbon contents in rock formation can be exactly obtained by quantitatively analysing the amount of probe molecules remaining on the nanoreporter collected at the production well. Moreover, identical concept was also used for the application on the detection of $\mathrm{H}_{2} \mathrm{~S}$ [64]. Here, $\mathrm{H}_{2} \mathrm{~S}$ detection was done by attaching polyvinyl alcohol functionalized carbon black with $\mathrm{H}_{2} \mathrm{~S}$ - sensor moieties termed as fluorescence probe. By injecting these hybrid molecules into hydrocarbon reservoir, the $\mathrm{H}_{2} \mathrm{~S}$ content can be determined based on the fluorescent enhancement of the $\mathrm{H}_{2} \mathrm{~S}$ sensor amends. Figure 4 shows the schematic mechanism for the detection of both the downhole hydrocarbon and $\mathrm{H}_{2} \mathrm{~S}$ content using carbon black nanoparticle-based nanosensors. 


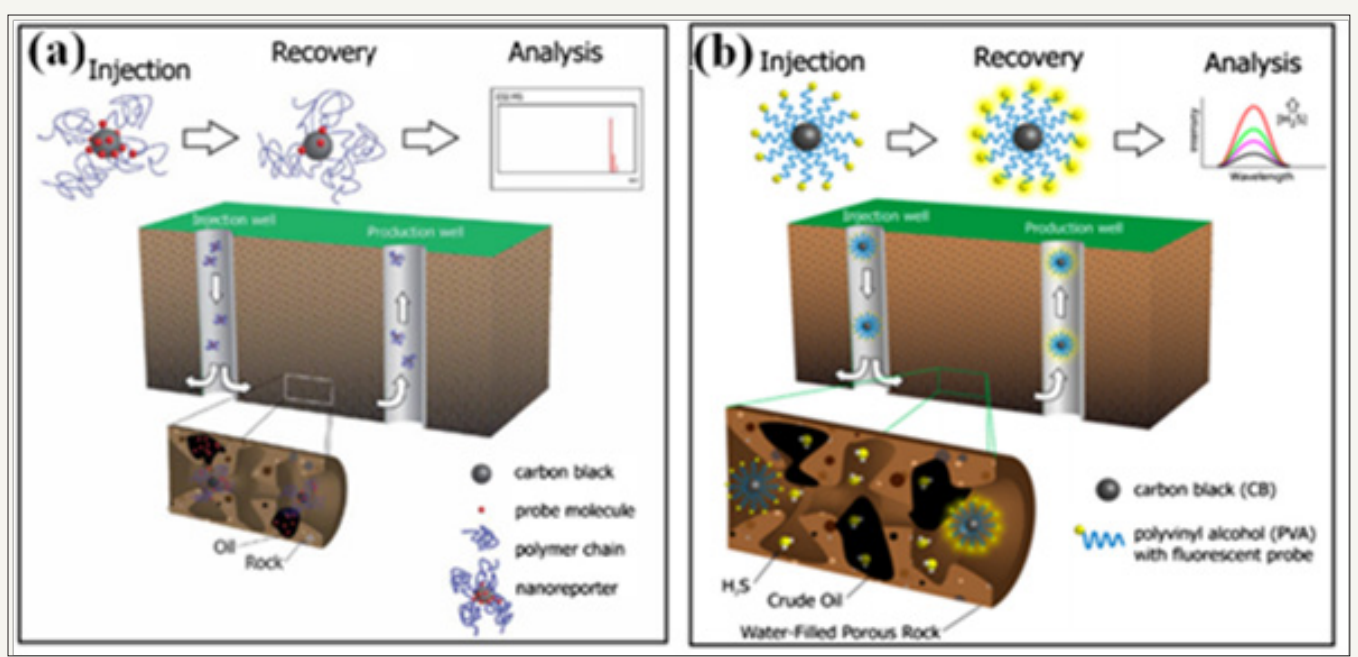

Figure 4: Schematic mechanism for the detection of (a) downhole hydrocarbon (b) H2S using carbon black nanoparticle-based nanoreports.

Kapusta et al. [64] explained the current nanosensors are in primarystage, there is stilla long way to achieve a passive nanosensor that does not required external power, and having the ability to store data. However, attaining this technology is authentic for reservoir exploration. Nanosensors could provide 100 times higher resolution from the subsurface comparing with other methods such as seismic, RF or EM. The sequence of the mechanical and acoustic petro physical data and high-resolution subsurface images and also acquiring other accurate information is possible from these nanosensors and not with traditional exploration methods, this current nanosensors will enable a better understanding of the reservoir and using the optimum oil recovery methods. In the view of Ragab [65], the better we know about the reservoir and more efficient the (nanosensors) process becomes. Implementing nanosensors constantly assist us to obtain updated and accurate data from the reservoir by employing the advanced measurement techniques. Exploration is the first step in development of field, which included determination of hydrocarbon presence in the subsurface environment by using advanced techniques such as seismic characterization, interpretation, logging, formation evaluation etc. As the oil and gas fields are getting shrink, in order to meet the demand of oil and gas, classification and arrangements have to be explored and developed. This requires going offshore or at higher depth in the onshore area. Using of nanoparticles for reservoir characterization certainly calls for more sophisticated methods of geophysical characterization with addressing the solutions to the problem of field development nevertheless drilling at optimum conditions [66]. Once the nanosensors are injected into in to the formation, will help to give information about both chemical and physical properties of the formation and as well as the $3 \mathrm{D}$ distribution of the formation and sensing mechanism like nanosensors for reservoir monitoring and surveillance [67]. nanosensors are excellent tools for and the formation of imaging contrast agents because of their excellent optical, magnetic and electrical properties [68]. Detection of Oil-Microbe using nano Optical fibres tool works on the principle of Resonance Raman
Spectroscopy (RRS).It can noted that microbes used in MEOR gives the exactly same response as RRS, both on surface as well as inside the reservoir. The detection of microorganism is based on recognition and excitation of chemotaxonomic markers present in them. Since microbes only survive on the oil-water interface, and clearly indicates the presence of microbes and depth will be sensed using depth sensor. Water being Raman inactive, at whatsoever depth thief zones (generally a channel with high absolute permeability) of water no spectrum will be observed and these thief zones can be detected and plugged thus deviating water to oilbearing zones. The tool will be dropped downhole by optical fibres, which can also transmit the reflected light to a computer on the surface to view the spectra. The nano optical fibres will carry the laser light in porous rock matrix, and receive the reflected light. The tool can also find different microorganisms present in reservoir. This helps in knowing reservoir parameters like temperature, pressure, salinity etc. since every type of microbe has a particular environment in which it can survive [69].

\section{Nanocoatings}

In oil and gas industry, the pipelines are made of low alloy steel, which helps to prevent drilling equipment's from wearing and gives resistance across the corrosion. Nanocoatings is more environmental friendly and efficient than anti-corrosion paints and other conventional coating methods used in the oil and gas industry. Nanocomposite coatings can be achieved using various base materials and coating nanomaterial. Some of the nanocomposite material is nitride nanocomposite coating, nanocomposite coatings of nickel/aluminium oxide, aluminium/ titanium oxide, aluminium/aluminium oxide, tungsten carbide/ nickel-cobalt, titanium oxide / nickel coating by electro-deposition and many more. Electro-deposition is highly used because of its low cost and the high performance nanocomposites, the application of electro-deposition is by using a template used for the making of nanowire comprising of different materials. It is concluded that if titanium oxide (TiO2) is blended in nickel (Ni), improves 
the performance of the $\mathrm{Ni}$ coating, however investigation of the resulting properties of an electroplated Ni nanocomposite that has different concentrations of $\mathrm{TiO} 2$ and differentiate with properties of Ni coating without incorporation of $\mathrm{TiO} 2$. It should be noted that the reinforced material could also be carbon nanotubes (CNTs), polymers, aluminium oxide, polytetrafluoroethylene and silicon carbide. However, TiO2 is one of the most used elements because of the resistance to oxidation, high strength and good corrosionresistant properties. Offshore, subsea valves are exposed to severe conditions including erosion, corrosion and high pressures, in such extreme cases, valves can be severely eroded within hours of service. To maintain safety and reduce shutdowns, requisite to furnish the protection for such valves. A WC-Cr Ni coating is an interesting coating alternative for corrosion resistant in seawater which also providing superior abrasion, erosion and sliding wear protection in nanostructure form. The pumps used in the oil and gas industries are frequently used to transport abrasive solids consigned in fluids. HVOF-applied WC-CoCr coating have been shown in improved service life and accuracy on a vertical shaft double entry pump with Francis type first stage impeller blades [76]. The authors of the study state that if the coating were applied to the entire runner, the time between overhaul would be increased by at least fourfold. Extraction of oil from the bituminous sands (oil sands) rely on bitumen feed pumps to transport the viscous and erosive fluid. Sync rude introduced a conventional HVOF-applied WC-Co coating on the pump impellers, which resulted in a six-fold increase in the life of the pumps, from 3500 service hours to more than 22,000 hours [77]. The translated into an annual savings of more than $\$ 280000$ per pump. Studies and development work later carried out by third parties to assess n-WC-Co coatings (in multimodal form) [78]. Syncrude, with their comprehensive inhouse experience in evaluating surface engineered samples, admit to act a three-body abrasion wear test on the n-WC-Co coatings. In Syncrude's database results showed that the n-WC-Co coatings performed well compared with all other thermal sprayed WC-Co coatings and even approached the values observed for welded (plasma transferred arc) deposits with comparable chemistries. WC and $\mathrm{CrC}$ based MMC coatings are greatly used on gas turbine engine (GTE) components; because of the high wear, resistance and durability commit these coatings to use in all sections of gas turbine engines, along with the compressor, combustion turbine and afterburner sections. The type of wear applied on carbide cermet-coated components is mainly grieving [79]. Nonetheless sliding, rubbing, erosion and brush wear are also come across. For this reason, the enhanced wear properties of n-carbide-based MMC coatings can be alluring for gas turbine engine components. In addition to the use of $n$-carbide-based MMC coatings on aero GTEs and in other aircraft components benefit from the same coatings. Nanostructured MMC coatings of the same composition as directly enforced on each component in conventional form may enhance the performance of components such as flap and slat tracks, landing gear, hydraulics, actuators, helicopter drive trains and propeller assemblies. Indeed there is a good evidence that n-WC-based MMC coating may further significantly increase the service life of the flap tracks on DHC-8 aircraft beyond the 40,000 cycles (one cycle representing one take-off and landing) provided by conventional WC-based MMC coatings [80]. This is based on the advancement in fatigue resistance noticed by Ibrahim and Berndt of n-WC-Co coatings [81] and the evidence is that rolling-contact fatigue is a major contributor to the deterioration of slat and flap track surfaces and such type of fatigue resistance coatings could adopt in oil and gas industry. Over the past few decades, the substitution of hard chrome plating has been a very important environmental concern. Several studies have shown that thermal sprayed (eg : HVOF) conventional WC-based MMC coatings can provide comparable and superior properties to HCP without the negative health or environmental implications associated with HCP. Given the superior resistance of $\mathrm{n}$-WC-based n-MC coating to impact and abrasion wear, there is a great reason to consider that the use of nanostructured coatings could farther develop on the results shown by their conventional counterparts, and reduced maintenance and improved reliability. The automotive industry has also benefited from the use of thermal spray coatings. One very interesting application, which has the potential for reducing energy costs and material wear in power train components, has been studied by several researchers [82]. These studies have demonstrated the advantages of APSdeposited conventional MMC coatings on cylinder liner surfaces of heavy-duty diesel truck engines. The advantages include reductions in wear, blow-by and oil consumption. Based on the results observed with n-MMC (i.e. WC-Co) coatings, there may be an opportunity to further improve on the positive attributes of the conventional MMC coating presented by Ernst \& Barbezat [83]. counterparts, and reduced maintenance and improved reliability. The automotive industry has also benefited from the use of thermal spray coatings. One very interesting application, which has the potential for reducing energy costs and material wear in power train components, has been studied by several researchers [82]. These studies have demonstrated the advantages of APS-deposited conventional MMC coatings on cylinder liner surfaces of heavyduty diesel truck engines. The advantages include reductions in wear, blow-by and oil consumption. Based on the results observed with n-MMC (i.e. WC-Co) coatings, there may be an opportunity to further improve on the positive attributes of the conventional MMC coating presented by Ernst \& Barbezat [83].

In addition there may also be an additional advantage in attaining a superior finish with reduced depth of cut with the nanostructured MMC coating. Other automotive components that could benefit from a similar nanostructured coating include cylinder rods, plungers and shafts; diesel valves and bearing areas. As in the aerospace industry, the automotive sector is interested in weight reduction using light materials and, for this reason; aluminium alloys can replace steel for purposes of matching its strength. However, there is a compromise with respect to wear resistance. To address this issue, a thermal sprayed hard coating such as $\mathrm{CrC}-\mathrm{NiCr}$ has been applied and tested against wear and corrosion. According to the authors of that

work, the coated prototypes passed both the dynamic and salt fog 
corrosion tests. Once again, based on the results of nanostructured cermet MMCs, one may expect to improve resistance against wear, impact and localized corrosion by using a nanostructured coating of the same material. Finally, the refurbishment of worn components is another area where nanostructured coatings could be beneficial. Refurbishment can lead to substantial cost savings. For automotive applications, thermal spray repair of worn shifter forks, crankshafts, bearing regions and transmission shafts have been successfully implemented. By using nanostructured metal coatings, one may be able to in some cases surpass the original performance characteristics of the repaired regions with respect to strength, wear and corrosion [84].

\section{Future Challenges and Directions}

The future is full of challenges. However, it is also obvious that the future is full of opportunities. The future possibilities for nanotechnology in oil drilling sector are identified as follows:

1. Nanotechnology enhanced materials that provide strength and endurance to increase performance and reliability in drilling, tabular goods, and rotating parts

2. Improved elastomers, critical to deep drilling and drilling in high temperature and high pressure environments

3. Corrosion management for offshore and onshore and facilities application

4. Environmental management for identification of environmentally friendly and sustainable of nanomaterials

5. Lighter-weight, rigid and stronger structural composites for drilling platforms/facilities and improve and betterperforming drilling.

6. Small/micro drill whole evaluation instruments to reduce drilling costs to provide greater environmental sensitivity because of drill waste [79].

\section{Conclusion}

Nanoparticles are expected to play an important role in addressing the stern drilling problems. These include high fluid loss, wellbore instability, and pipe sticking problem and drag reduction. Future drilling operations are likely to face even greater technical challenges due to the exploitation of unconventional reservoirs and deep-water resources [80] Due to their unique characteristics, nanomaterials resolves drilling problems that cannot be solved with traditional approaches. Nanoscale drilling fluid additives and nanofluids are potential for oil well drilling operations and enables to push the limits of the existing drilling technology and endow with cost effective and technically viable drilling operations. Future drilling operations require new materials that can meet the special requirements of the drilling in highly deviated wells, horizontal wells and complex deep wells. In the near future, nanomaterials will have an essential application value, it will make a new breakthrough in enhancing efficiency of drilling operations, and improve the overall competitiveness of the oil and gas industry [81]. The catalyst in hydrocracking processes reduces coke formation in hydrogen rich atmosphere and therefore, catalytic lifetime could be prolong with high catalytic activity. Therefore, a strategic nanocatalyst development is essential to obtain high activity and selectivity for hydrocracking of heavy oils. Simultaneously, deactivation caused by metal impurities and physical damages should also be considered [82].

Nanoparticles as adsorbent and catalysts are potential for enhancing heavy oil upgrading and recovery. However, facing a number of limitations and challenges in oil industry. Synthesis of nanoparticles could be performed via various techniques. However, mass production of required nanoparticles and availability of surface facilities, stability of produced volume and control over the size of the particles are some of the important issues that should be addressed in any industrial applications. Cost is also an important acquire hitech control systems to avoid or mitigate any associated risks due to the nature of high pressure and temperature reaction conditions. For in-situ application and since the reaction media is porous, transport behaviour of nanoparticles inside the porous media, deposition tendency on the surface and consequent permeability damage as well as pressure drop across the medium are quite important factors. Along with experimental studies, mathematical modelling of nanoparticle penetration as well as reaction kinetics of in-situ heavy oil inside the target mediums in reaction conditions. Presence of nanoparticles inside the porous media and providing appropriate reaction conditions with required elements including hydrogen would result recovery improvement as well as considerable quality enhancement shows very promising future for the nanoparticles in-situ implementation. Furthermore, nanoparticle based fluids could be employed successfully for changing reservoir wettability from an oil-wet to a water-wet condition. Injection of nanofluids into porous media caused an inhibition in the agglomeration, precipitation, and deposition of asphaltenes on the rock surfaces and hence led to improvements in oil recovery. However, environmental challenges should be scrutinized in a very good depth to mitigate any associated risks regarding the mass usage of nanoparticles. In this regards, recovery and re-using the nanoparticles could be very beneficial in terms of economy and eco-friendly.

\section{Acknowledgement}

MS, VJB and SR would like to thanks LRF (Llyods Register Foundation, United Kingdom) for the financial support.

\section{References}

1. Mokhatab S, AFresky M, Islam MR (2006) Applications of nanotechnology in oil and gas E\&P. J Pet Technol Online 58: 48.

2. Muraza O, Galadima A (2015) Aquathermolysis of heavy oil: a review and perspective on catalyst development. Fuel 157: 219-231.

3. Khalil M, Lee RL, Liu N (2015) Hematitenanoparticles in aquathermolysis: a desulphurization study of thiophene. Fuel 145: 214-220.

4. Wei L, Hua ZJ, Hua QJ (2007) Application of nano-nickel catalyst in the viscosity reduction of Liaohe extra-heavy oil by aquathermolysis. J Fuel ChemTechnol 35: 176-180.

5. Chen Y, Wang Y, Lu J, Wu C (2009) The viscosity reduction of nanokeggin- $\mathrm{K}_{3} \mathrm{PMo}_{12} \mathrm{O}_{4}$ in catalytic aquathermolysis of heavy oil. Fuel 88(8): 
$1426-1434$

6. Kong X, Ohadi M (2010) Applications of micro and nano technologies in the oil and gas industry - overview of the recent progress, Society of Petroleum Engineers, SPE-138241-MS, Abu Dhabi International Petroleum Exhibition and Conference, Abu Dhabi, UAE. pp. 1-11.

7. Tretheway DC, Meinhart CD (2002) Apparent fluid slip at hydrophobic microchannel walls. Physics of Fluids 14: L9-L12.

8. Prodanovic M, Ryoo S, Rahmani AR, Kuranov RV, Kotsmar C, et al. (2010) Effects of magnetic field on the motion of multiphase fluids containing paramagnetic particles in porous media, Society of Petroleum Engineers, SPE Improved Oil Recovery Symp Tulsa, Oklahoma. SPE 129850, pp $1-19$.

9. Yu H, Kotsmar C, Yoon KY, Ingram DR, Johnston KP, etal. (2010) Transport and retention of aqueous dispersions of paramagnetic nanoparticles in reservoir rocks, Society of Petroleum Engineers, SPE Improved Oil Recovery Symposium, Tulsa, Oklahoma, USA. SPE-129887-MS, pp. 1-21.

10. Yu H, Yoon KY, Neilson BM, Bagaria HG, Worthen AJ, et al. (2014) Transport and retention of aqueous dispersions of superparamagnetic nanoaparticles in sandstone. Journal of Petroleum Science and Engineering 116: 115-123.

11. Zhang T, Davidson D, Bryant SL, Huh C (2010) Nanoparticle-stabilized emulsions for applications in enhanced oil recovery, Society of Petroleum Engineers, SPE Paper 129885, SPE Improved Oil Recovery Symp, Tulsa, pp. 1-18.

12. Zhang T, Espinosa D, Yoon KY, Rahmani AR, Yu H, et al. (2011) Engineered nanoparticles as harsh-condition emulsion and foam stabilizers and as novel sensors offshore technology conference, Houston, Texas, USA, OTC-21212-MS, pp. 1-15.

13. Ratner M, Ratner D (2002) Nanotechnology: A gentle introduction to the next big idea, Prentice Hall, ISBN-10: 0-13-101400-5, pp. 1-208

14. Jackson SA (2005) Innovation and human capital energy security and the quiet crisis. American Petroleum Institute.

15. Pandey RK, Krishna S, Rana J, Hazarika NK (2016) Emerging applications of nanotechnology in oil and gas industry. International Journal for Technological Research In Engineering 3(10): 2347-4718.

16. Engeset B (2012) The potential of hydrophilic silica nanoparticles for EOR purposes, Norwegian University of Science and Technology, Norway.

17. Sun Y, Zhang G, Chen Z, Gai (2017) Application of nanoparticles in enhanced oil recovery: a critical review of recent progress. Energies 10(3): 345

18. Suleimanov BA, Ismailov FS, Veliyev EF (2011) Nanofluid for enhanced oil recovery. Journal of Petroleum Science and Engineering 78(2): 431437.

19. Roustaei, J. Moghadasi, H. Bagherzadeh, A. Shahrabadi (2012) An experimental investigation of polysilicon nanoparticles' recovery efficiencies through changes in interfacial tension and wettability alteration. Society of Petroleum Engineers, SPE 156976, SPE International Oilfield Nanotechnology Conference held in Noordwijk, Netherlands, pp. 1-7.

20. Zargartalebi M, K R, B N (2015) Enhancement of surfactant flooding performance by the use of silica nanoparticles. Fuel 143: 21-27.

21. Magzhi A, Kharrat ZM, Mohebbi A, Ghazanfari MH (2014) The impact of silica nanoparticles on the performance of polymer solution in presence of salts in polymer flooding for heavy oil recovery. Fuel 123: 123-132.

22. Lei S, Hendraningrat L, Torsaeter 0 (2013) Improved oil recovery by hydrophilic silica nanoparticles suspension: 2 phase flow experimental studies, IPTC 2013 In Proceedings of the IPTC 2013: International Petroleum Technology Conference, European Association of Geoscientists \& Engineers, Beijing, China, pp. 1-15.
23. Hendraningrat L, Li S, Torsater 0, (2013) Effect of some parameters influencing enhanced oil recovery process using silica nanoparticles: An experimental investigation. Society of Petroleum Engineers, SPE Reservoir Characterization and Simulation Conference and Exhibition, Abu Dhabi, UAE, pp. 1-10.

24. Hendraningrat $\mathrm{L}$, Torsæter $\mathrm{O}$ (2014) Understanding fluid-fluid and fluidrock interactions in the presence of hydrophilic nanoparticles at various conditions, Society of Petroleum Engineers. SPE-171407-MS, SPE Asia Pacific Oil \& Gas Conference and Exhibition, Adelaide, Australia, pp. 1-18.

25. Anssari SA, Barifcani A, Wang S, Maxim L, Iglauer S (2016) Wettability alteration of oil-wet carbonate by silica nanofluid. J Colloid Interface Sci 461: 435-442.

26. Bayat AE, Junin R, Samsuri A, Piroozian A, Hokmabadi M (2014) Impact of metal oxide nanoparticles on enhanced oil recovery from limestone media at several temperatures. Energy Fuels 28(10): 6255-6266.

27. Hendraningrat L, Torsæter 0 (2015) Metal oxide-based nanoparticles: revealing their potential to enhance oil recovery in different wettability systems. Appl Nanosci 5(2): 181-199.

28. Shah RD (2009) Application of nanoparticle saturated injectant gases for EOR of heavy oils. Society of Petroleum Engineers, SPE Annual Technical Conference and Exhibition, New Orleans, Louisiana, pp.1-12.

29. Ogolo NA, Olafuyi OA, Onyekonwu MO (2012) Enhanced oil recovery using nanoparticles. Society of Petroleum Engineers, SPE-160847-MS, SPE Saudi Arabia Section Technical Symposium and Exhibition, AlKhobar, Saudi Arabia, pp. 1-9.

30. Myloslavskyy O, Danilenko I, Yashchishyn I, Lyubchik S, Konstantinova $\mathrm{T}$ (2013) Surface effects in formation and application nano- particles based on Zirconia.

31. Kothari N, Raina B, Chandak K, Iye V, Mahajan Hp (2010) Application of ferrofluids for enhanced surfactant flooding in IOR. Society of Petroleum Engineers, SPE-138241-MS SPE EUROPEC/EAGE Annual Conference and Exhibition, Society of Petroleum Engineers, Barcelona, Spain, pp. $1-11$.

32. Yahya N, Kashif M, Nasir N, Akhtar MN, Yusof NM (2012) Cobalt ferrite nanoparticles: an innovative approach for enhanced oil recovery application. J Nano Res 17: 115-126.

33. Chandran K (2013) Multiwall carbon nanotubes (MWNT) fluid in eor using core flooding method under the presence of electromagnetic waves, Petronas University of Technology, Malaysia.

34. Wang L, Wang Z, Yang H, Yang G (1999) The study of thermal stability of the SiO2 powders with high specific surface area. Mater Chem Phys 57: 260-263.

35. Wang H, Huang L, Holmberg BA, Yan Y (2002) Nanostructured zeolite $4 \mathrm{~A}$ molecular sieving air separation membranes. Chem Commun 16: 1708-1709.

36. Skauge T, Spildo K, Skauge A (2010) Nano-sized particles for EOR. Society of Petroleum Engineers, SPE Improved Oil Recovery, Oklahoma, USA

37. Luo D, Wang F, Zhu J, Cao F, Liu Y, et al. (2016) Nanofluid of graphenebased amphiphilic Janus nano sheets for tertiary or enhanced oil recovery: high performance at low concentration. Proc Natl Acad Sci U S A 113(28): 7711-7716

38. Hashemi R, Nassar NN, Almao PP (2014) Nanoparticle technology for heavy oil in-situ upgrading and recovery enhancement: Opportunities and challenges. Applied Energy 133: 374-387.

39. Newson E (1975) Catalyst deactivation due to pore-plugging by reaction products. Ind Eng ChemProc Des Dev 14(1): 27-33.

40. Maity SK, Ancheyta J, Marroquin G (2010) Catalytic aquathermolysis used for viscosity reduction of heavy crude oils: a review. Energy Fuel 
24(5): 2809-2816

41. Campelo JM, Li D, Luque R, MMarinas J, Romero AA (2009) Sustainable preparation of supported metal nanoparticles and their application in catalysis. Chem Sus Chem 2(1): 18-45.

42. Shokrlu YH, Babadagli T (2011) Transportation and interaction of nano and micro size metal particles injected to improve thermal recovery of heavy-oil, in: In Proceedings of the SPE Annual Technical Conference and Exhibition, Denver, USA.

43. Thompson J, Vasquez A, Hill JM, Pereira-Almao P (2008) The synthesis and evaluation of up-scalable molybdenum based ultra dispersed catalysts: effect of temperature on particle size. Catal Lett 123: 16-23.

44. Lemaitre J, Menon PG, Delannay F (1984) The measurement of catalyst dispersion. In: Characterization of heterogeneous catalysts, Marcel Dekker, New York, USA, pp. 325-327.

45. Velu S, Gangwal SK (2006) Synthesis of alumina supported nickel nanoparticle catalysts and evaluation of nickel metal dispersions by temperature programmed desorption. Solid State Ionics 177(7-8): 803811.

46. Okamoto Y, Odawara M, Onimatsu H, Imanaka T (1995) Preparation and catalytic properties of highly dispersed molybdenum and cobaltmolybdenum sulfide catalysts supported on alumina. Ind EngChem Res 34(11): 3703-3712.

47. Yoosuk B, Kim JH, Song C, Ngamcharussrivichai C, Prasassarakich $\mathrm{P}$ (2008) Highly active $\mathrm{MoS}_{2}, \mathrm{CoMoS}_{2}$ and $\mathrm{NiMoS}_{2}$ unsupported catalysts prepared by hydrothermal synthesis for hydrodesulfurization of 4,6-dimethyldibenzothiophene. Catal Today 130(1): 14-23.

48. Capek I (2004) Preparation of metal nanoparticles in water-in-oil (w/o) micro emulsions. Adv Colloid Interface Sci 110(1-2): 49-74.

49. Pereira P, Marzin R, Zacarias L, Cordova J, Carrazza J (1999) Steam conversion process and catalyst. Google Patents, US5885441A.

50. Vasquez A (2009) Synthesis, characterization and model reactivity of ultra dispersed catalysts for hydroprocessing. University of Calgary, Alberta.

51. Hashemi R, Nassar NN, Almao PP (2012) Transport behavior of multimetallicultradispersed nanoparticles in an oil-sands-packed bed column at a high temperature and pressure. Energy Fuels 26(3): 16451655.

52. Ebrahimynejad M, Haghighi M, Asgari N (2014) Ultrasound assisted synthesis and physicochemical characterizations of fluorine-modified $\mathrm{CoMo} / \mathrm{Al}_{2} \mathrm{O}_{3}$ nanocatalysts used for hydrodesulfurization of thiophene. J Nanosci Nanotechnology 14(9): 6848-6857.

53. Mohammed MI, Razak AAA, Shehab MA (2017) Synthesis of nanocatalys for hydrodesulfurization of gasoil using laboratory hydrothermal rig. Arabian Journal for Science and Engineering 42(4): 1381-1387.

54. Montoya T, Argel BL, Nassar NN, Franco CA, Cortes FB (2016) Kinetics and mechanisms of the catalytic thermal cracking of asphaltenes adsorbed on supported nanoparticles. Pet Sci 13(3): 561-571.

55. Hosseinpour M, Fatemi S, Ahmadi SJ (2015) Catalytic cracking of petroleum vacuum residue in supercritical water media: impact of a- $\mathrm{Fe}_{2} \mathrm{O}_{3}$ in the form of free nanoparticles and silica-supported granules. Fuel 159: 538-549.

56. Golmohammadi M, Ahmadi SJ, Towfighi J (2016) Catalytic cracking of heavy petroleum residue in supercritical water: study on the effect of different metal oxide nanoparticles. J Supercrit Fluid 113: 36-143

57. Ryoo S, Rahmani AR, Yoon KY, Prodanovic M, Kotsmar C, et al. (2012) Theoretical and experimental investigation of the motion of multiphasefluids containing paramagnetic nanoparticles. J Pet Sci Eng 81: $129-144$

58. Kotsmar C, Yoon KY, Yu H, Ryoo SY, Barth J, et al. (2010) Stable citrate-
coatedIron oxide superparamagnetic nanoclusters at high salinity. Ind Eng Chem Res 49(24): 12435-12443.

59. Rahmani AR, Athey AE, Ahmadian M, Wilt M, Chen J, et al. (2015) Crosswell magnetic sensing of superparamagnetic nanoparticles forsubsurface application. Society of Petroleum Engineers 20: 1-16.

60. Park YC, Paulsen J, Nap RJ, Whitaker RD, Mathiyazhagam V, et al. (2014) Adsorption of superparamagnetic iron oxide nanoparticles on silica andcalcium carbonate sand. Langmuir 30: 784-792.

61. Brown KA, Vassilliou CC, Issadore D, Berezovsky J, Cima MJ, et al. (2010) Scaling of transverse nuclear magnetic relaxation due to magneticnanoparticle aggregation. J Magn Magn Mater 322: 3122-3126.

62. Hwang CC, Wang L, Lu W, Ruan G, Kini GC, et al. (2012) Highly stable carbon nanoparticles designed for downhole hydrocarbon detection. Energy Environ Sci 5: 8304-8309.

63. Hwang CC, Ruan G, Wang L, Zheng H, Samuel EL, et al. (2014) Carbonbased nanoreporters designed for subsurface hydrogen sulfide detection. ACS 6: 652-7658.

64. Kapusta S, Balzano L, Riele PMT (2012) Nanotechnology applications in oil and gas exploration and production. International Petroleum Technology Conference.

65. Ragab AMS (2014) Investigating the potential of nanomaterial for enhanced oil recovery: state of art. J Sci Technol 6: 25-40.

66. Barron AR (2008) Nanotechnology for the oil and gas industry, Rice University, Houston, Texas, USA, pp. 1-172.

67. Kapusta S, Balzano L, Riele P (2011) Nanotechnology applications in oil and gas exploration and production, International Petroleum Technology Conference, IPTC-15152-MS, pp. 1-5.

68. Krishnamoorti R (2006) Extracting the benefits of nanotechnology for the oil industry. Journal of Petroleum Technology 58: 24-26.

69. (2018) $8^{\text {th }}$ Biennial International conference \& Exposition on petroleum Geophysics. Nano-Science \& Technology in Upstream, P. 29.

70. Cropper MS, Schmid RK, Mohanty M (2000) Increasing pump life in abrasive service through state-of-the-art surface protection In: Proceedings of the Seventeenth International Pump Users Symposium, 87101.

71. Lima RS, Marple BR, Li H, Khor KA, Therm J (2006) Spray Technol, Biocompatible nanostructured high velocity oxyfuel sprayed titania coating: deposition, characterization, and mechanical properties 15: 623-627.

72. Kim GE, Addona T (2001) Synthesis of nanostructured Al alloys via noncryogenic milling. ONR Program Review on Nanostructured Materials.

73. Koiprasert H, Niranatlumpong P, Dumrongrattana S (2004) Thermally sprayed coating for protection of fretting wear. J Sci Res Chula Univ 29: 105-118.

74. Ruggiero PF (2005) High velocity oxygen fuel coatings: a way to extend component life.

75. Ibrahim A, Berndt CC (2004) Fatigue and mechanical properties of nanostructured WC-Co coatings.

76. Gerard B (2006) Application of thermal spraying in the automobile industry. Surf Coat Technol 201: 2028-2031.

77. Ernst P, Barbezat G (2008) Thermal spray applications in powertrain contribute to the saving of energy and material resources. Surf Coat Technol 202: 4428-4431.

78. Wank A, Wielage B, Grund T, Rupprecht C, Angermann K (2005) Local wear protection for demountable automotive aluminum draw bars by thermal spray coatings, thermal spray connects: explore its surfacing potential. ASM International, pp. 118-121. 
79. Nabhani N, Emami M (2012) The potenial impact of nanomaterials in oil drilling industry nanocon, Brno, Czech Republic, Europe.

80. Kasiralvalad E (2014) The great potential of nanomaterials in drilling \& drilling fluid applications. Int J Nano Dimens 5(5): 463-471.

81. Sahu R, Song BJ, Im JS, Jeon YP, Lee CW (2015) A review of recent advances in catalytic hydrocracking of heavy residues. Journal of Industrial and Engineering Chemistry 27: 12-24
82. Hashemi R, Nassar NN, Pereira PA (2014) Nanoparticle technology for heavy oil in-situ upgrading and recovery enhancement: Opportunities and challenges. Applied Energy 133: 374-387.

\section{Your subsequent submission with Crimson Publishers} will attain the below benefits

- High-level peer review and editorial services

- Freely accessible online immediately upon publication

- Authors retain the copyright to their work

- Licensing it under a Creative Commons license

- Visibility through different online platforms

- Global attainment for your research

- Article availability in different formats (Pdf, E-pub, Full Text)

- Endless customer service

- Reasonable Membership services

- Reprints availability upon request

- One step article tracking system 